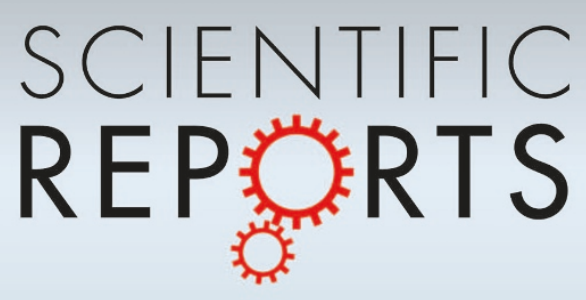

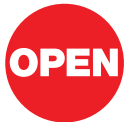

SUBJECT AREAS:

URBAN ECOLOGY

ECOLOGY

ASTRONOMY AND PLANETARY

SCIENCE

ENVIRONMENTAL SCIENCES

Received

1 March 2013

Accepted

2 April 2013

Published

24 April 2013

Correspondence and requests for materials should be addressed to

T.W.D. (Thomas.

Davies@exeter.ac.uk)

\section{Artificial light alters natural regimes of night-time sky brightness}

\author{
Thomas W. Davies, Jonathan Bennie, Richard Inger \& Kevin J. Gaston
}

Environment and Sustainability Institute, University of Exeter, Penryn, Cornwall TR 10 9EZ, U.K.

Artificial light is globally one of the most widely distributed forms of anthropogenic pollution. However, while both the nature and ecological effects of direct artificial lighting are increasingly well documented, those of artificial sky glow have received little attention. We investigated how city lights alter natural regimes of lunar sky brightness using a novel ten month time series of measurements recorded across a gradient of increasing light pollution. In the city, artificial lights increased sky brightness to levels six times above those recorded in rural locations, nine and twenty kilometers away. Artificial lighting masked natural monthly and seasonal regimes of lunar sky brightness in the city, and increased the number and annual regime of full moon equivalent hours available to organisms during the night. The changes have potentially profound ecological consequences.

T he widespread use of artificial lighting to illuminate the night-time environment has raised significant concerns regarding its aesthetic ${ }^{1-4}$, environmental ${ }^{5-8}$, and human health impacts ${ }^{2,8}$. Yet despite measures to improve economic efficiency and mounting pressure from the astronomical community, light pollution persists, continues markedly to grow in spatial extent ${ }^{9}$, and is broadening in its spectral characteristics ${ }^{7}$.

Aesthetically, sky glow (artificial light which is scattered and reflected back to earth by the atmosphere) obscures our view of natural starlight and moonlight ${ }^{10,11}$. In 2001 it was estimated that $60 \%$ of the world's population inhabited areas affected by artificial sky glow $^{3}$, leading astronomers to campaign for darker skies in urban and suburban regions ${ }^{1}$, and the establishment of the first international dark sky parks for recreational stargazing ${ }^{12}$. Associated with increasingly urbanised lifestyles, this loss of naturally lit sky arguably contributes to the 'extinction of experience' or the disengagement of people from the natural environment ${ }^{13}$, compounding efforts to engage the public on issues of environmental concern.

In addition, sky glow may be having environmental impacts that have so far remained largely unexplored, while those of direct artificial lighting are much better understood and increasingly well documented. The impacts of direct artificial light include navigational disorientation of birds ${ }^{14,15}$, turtles $^{16,17}$ and invertebrates ${ }^{18,19}$, the displacement and concentration of selected foraging habitat in bats ${ }^{20,21}$ and birds $^{22}$, the extension of foraging times in birds $^{22-24}$, and changes to the composition of invertebrate communities ${ }^{25}$. Added to this, the potential effects of sky glow include artificially increasing the amount of ambient light and time available for foraging ${ }^{26,27}$, interfering with celestial light patterns used in navigation ${ }^{28}$, and the disruption of temporal activity patterns linked to daily, monthly and annual lunar rhythms in sky brightnes ${ }^{29-32}$. Understanding how sky glow alters natural regimes of sky brightness is therefore fundamental to investigating its environmental impacts.

Natural regimes of night-time sky brightness are influenced by the harmonic movements of the astronomical bodies. During each month, sky brightness resulting from lunar rhythms varies from its highest when the moon is full and above the horizon, to its lowest when the moon is new ${ }^{33}$. At seasonal time scales, variation in the altitude of the full moon results in winter nights being more brightly lit by the lunar disc than summer nights, while at longer time scales the 18.6 year cycle of variation in the moon's orbit also affects night-time sky brightness regimes. These natural predictable regimes in sky brightness provide organisms with a lunar clock with which to synchronise activities. In addition, the variation in night-time length at higher latitudes gives rise to predictable annual regimes in the amount of moonlit hours available to conduct activities such as foraging and reproduction in any given month. Artificial light pollution may interfere with monthly regimes in sky brightness, and annual regimes in the amount of sufficiently lit foraging time available to nocturnal species.

Here we determine how artificial light pollution alters natural sky brightness regimes. First, we assess whether artificial lighting changes monthly and seasonal regimes in sky brightness compared to those which occur naturally as a result of lunar rhythms. Second, we determine how this decoupling affects the number of full 
moon brightness equivalent hours available for nocturnal activity across the year. Throughout, we are considering only the diffuse light scattered across the sky dome, rather than the direct light from the lunar disc itself.

As a case study, sky brightness was monitored for 10 months at three locations which varied in proximity to Plymouth city centre, UK (Figure 1). Changes in sky brightness resulting from temporal variation in moon altitude and phase were then modelled for the same period. The observed values and model predictions of sky brightness were compared to understand how artificial light pollution alters monthly and annual regimes of night-time sky brightness at each of the three locations. The number of full moon equivalent sky brightness hours available for activity per night in each month was compared between the three sampling locations. This was quantified as the number of hours when the sky was brighter than the $3^{\text {rd }}$ quartile observation made when the moon is between three-quarters and full $\left(<45^{\circ}\right.$ phase angle) at a location where sky brightness was predominantly governed by celestial bodies.

\section{Results}

Night time sky brightness during the observation period was on average 8 times greater in Plymouth city centre $(0.048 \pm 0.001 \mathrm{SE}$ $\left.\mathrm{cd} \mathrm{m}^{-2}, \mathrm{SD}=0.051\right)$ compared to locations $8.6(0.006 \pm 0.003 \mathrm{SE} \mathrm{cd}$

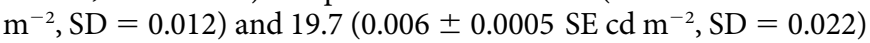
$\mathrm{km}$ away ( $\mathrm{SE}=$ Standard Error, $\mathrm{SD}=$ Standard Deviation). Monthly variation in sky brightness due to the orbit of the moon around the earth (phase) and seasonal variation in maximum sky brightness due to variation in the altitude of full moon (Figure $2 \mathrm{~d}$ ) were easily recognised in both the $19.7 \mathrm{~km}$ (Figure 2a) and $8.6 \mathrm{~km}$ (Figure 2b) sampling locations. By contrast, natural rhythms of lunar sky brightness were not evident in observations recorded from the sky over Plymouth city centre (Figure 2c). Observations of sky brightness on nights of lunar activity (when the moon was above the horizon) over the sampling period were significantly correlated with predicted lunar sky brightness at all three locations (Pearson correlation; city centre: $\mathrm{r}=0.16, \mathrm{df}=1186, \mathrm{p}<0.0001 ; 8.6 \mathrm{~km}: \mathrm{r}=0.70, \mathrm{df}=1106$, $\mathrm{p}<0.0001 ; 19.7 \mathrm{~km}: \mathrm{r}=0.59, \mathrm{df}=1036, \mathrm{p}<0.0001)(\mathrm{df}=$ degrees of freedom). However, the strength of this correlation was markedly lower in Plymouth city centre compared to both the $8.6 \mathrm{~km}$ and the $19.7 \mathrm{~km}$ sampling locations, indicating that observed sky brightness regimes were less synchronised with predicted regimes in lunar sky brightness in the city (Figures 2 and 3). Indeed, while the two rural locations displayed a clear linear increase of observed with predicted sky brightness (Figure 3a and b, note logarithimic y axis), observed scaled with predicted sky brightness in a polygonal relationship in Plymouth city centre (Figure 3d). Here, minimum observed sky brightness was determined by predicted lunar sky brightness regimes, while maximum brightness was not. The variation in observed sky brightness above the minimum is likely a result of the influence of artificial lights and their interaction with cloud which can amplify sky brightness in the city by reflecting artificial light back towards the earth's surface ${ }^{34}$.

The location of this study in northern temperate latitudes means that astronomical night length varies substantially throughout the year (Figure 4). Hence the average nightly number of full moon equivalent hours was higher in winter across all three locations. The difference in the sky brightness regimes in Plymouth city centre resulted in significantly more full moon equivalent hours per night, compared to the two rural locations (ZAP, hours $\sim$ site: $\mathrm{df}=4, \chi^{2}=$ 535.7, $\mathrm{p}<0.0001$ ) with the magnitude of this increase being more pronounced in winter than summer months (Figure 4). In the city, the presence of artificial lighting means that the annual regime in the average nightly hours of full moon equivalent sky brightness more closely approximates the regime in astronomical night length, while in the countryside this remains linked to regimes of lunar periodicity

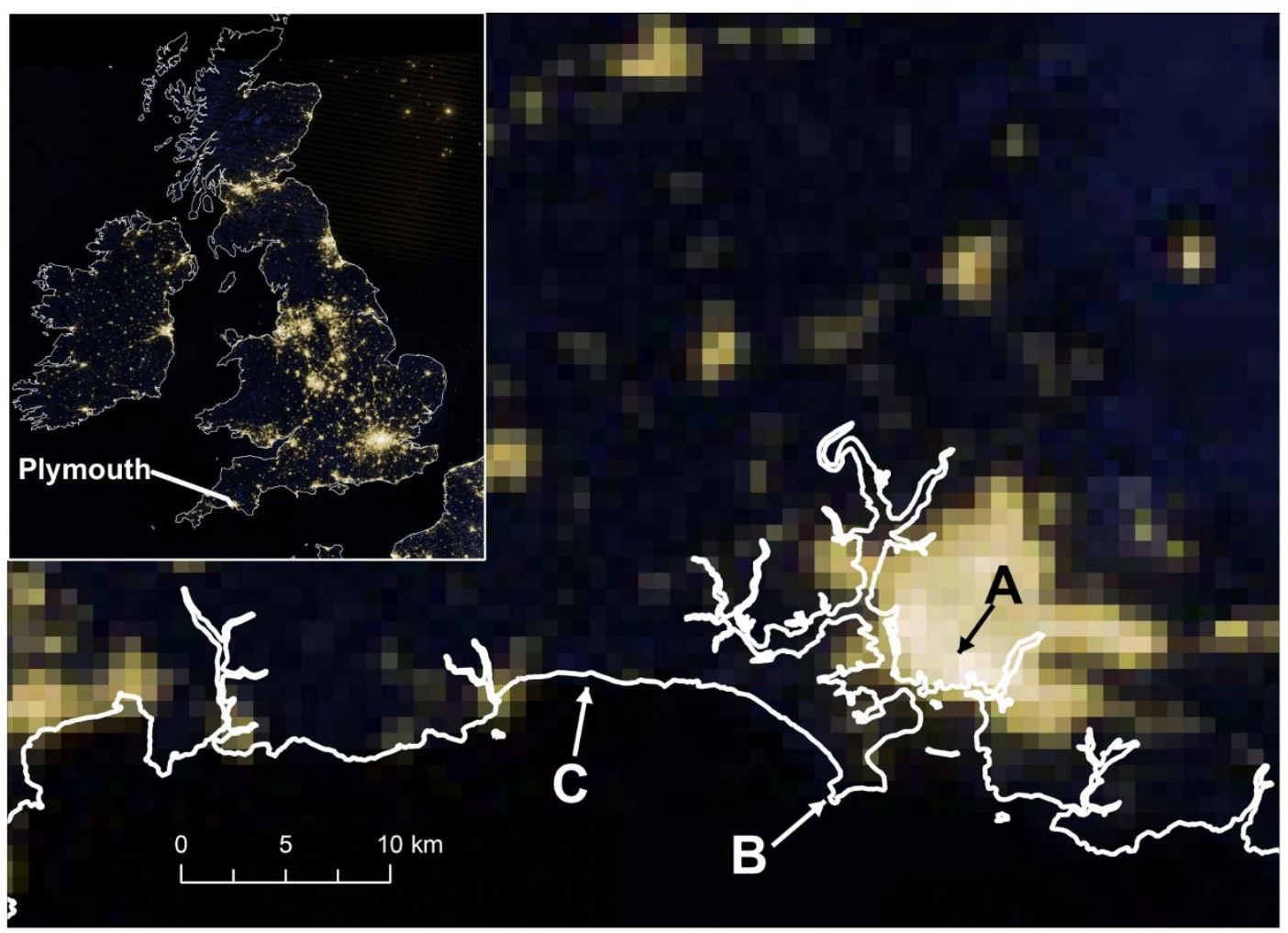

Figure 1 Sampling locations in relation to artificial light pollution. SQM-LU-DLs were deployed in Plymouth city centre (A), $8.6 \mathrm{~km}$ from the city centre (B), and $19.7 \mathrm{~km}$ from the city centre (C). Image acquired by the Suomi National Polar-orbiting Partner satellite on March 27, 2012. Downloaded from http://earthobservatory.nasa.gov/IOTD/view.php?id=78674 on $13^{\text {th }}$ December 2012, georectified using ArcGIS v9.2. 

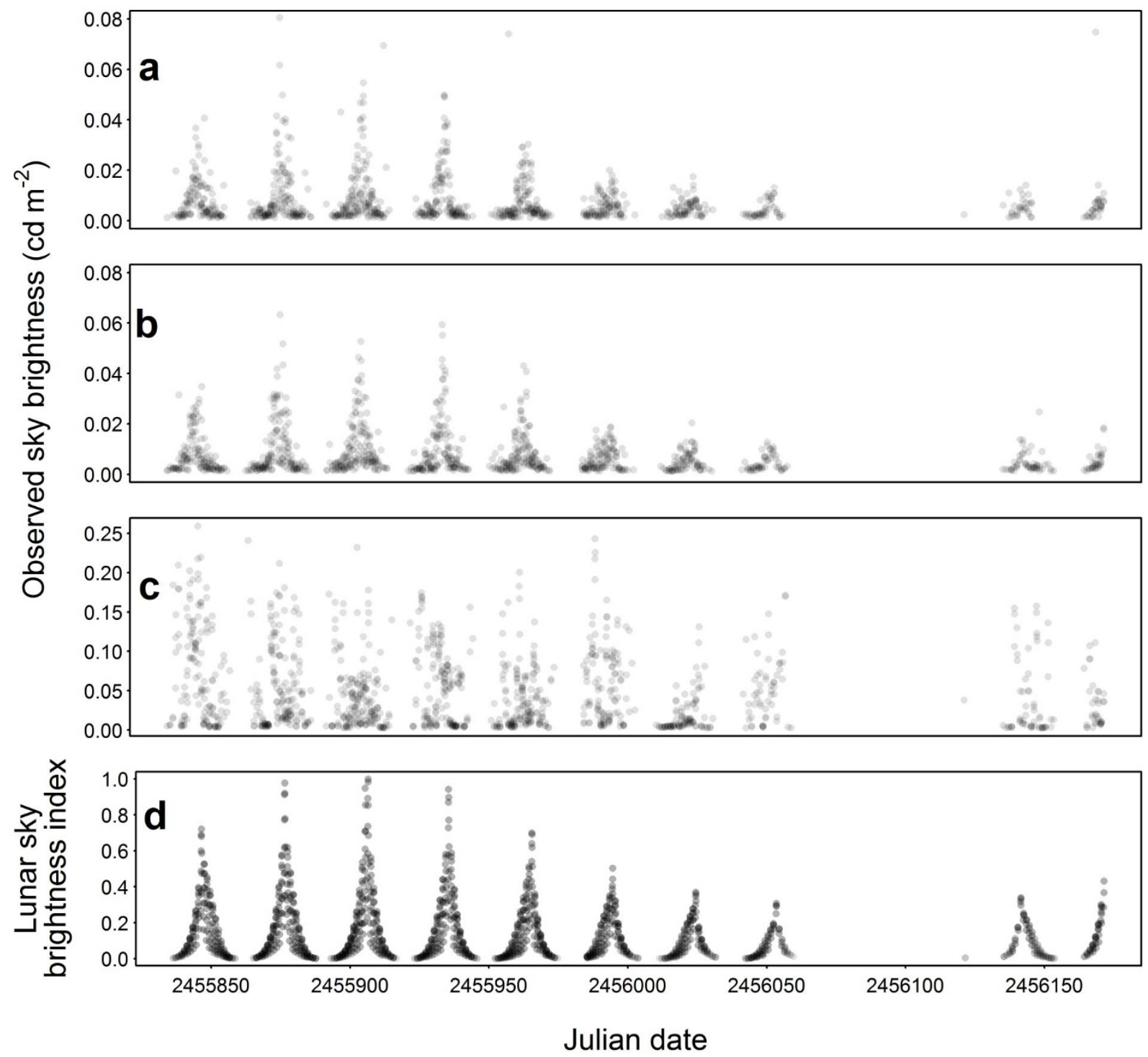

Figure $2 \mid$ City lights disrupt regimes in lunar night-time sky brightness. Observed regimes of night-time sky brightness (grey points) recorded $19.7 \mathrm{~km}$ (a), $8.6 \mathrm{~km}$ (b) and $0 \mathrm{~km}$ (c) from Plymouth city centre are compared to the predicted natural regime of lunar sky brightness (d). Points are plotted with transparency to provide information about density (darker regions correspond to denser aggregations of points). Observations are plotted for the period between $01 / 10 / 2011$ and $31 / 07 / 2012$. Note that the gap in the data around 2456100 julian date occurs because, at our locations, astronomical night does not occur during June. Each point represents an hourly recording of sky brightness (a-c) or predicted relative sky brightness (d), with recordings made when the moon was below the horizon, and when SQMs threshold at maximum brightness omitted (see methods).

(Figure 4). This difference in the regime of average nightly hours of full moon equivalent sky brightness was significant between sites at the $95 \%$ confidence level (ZAP, hours $\sim$ site*month: $\mathrm{df}=32, \chi^{2}=$ $46.6, \mathrm{p}=0.05)$.

\section{Discussion}

The results of this study demonstrate that artificial sky glow from city lights substantially alters natural regimes of night-time sky brightness. The presence of artificial lights increases the average intensity of night-time sky brightness, masks natural regimes resulting from lunar periodicity, and increases the number of full moon equivalent hours of sky brightness throughout the night. This latter effect is greater in winter than in summer at higher latitudes, resulting in a change in the annual regime of full moon equivalent hours of sky brightness.

The astronomical community have typically led the campaign for the reduction of artificial sky glow on aesthetic and scientific grounds ${ }^{1}$. This study has highlighted how artificial lights alter natural regimes of sky brightness at different temporal scales. These changes may be having deleterious impacts on a variety of ecological processes which are informed by the periodicity in the brightness of the night sky. Increasing the hours of full moon equivalent sky brightness per night may extend or reduce the time available to organisms to perform activities. For example, a very large number of species are nocturnal or facultatively nocturnal, with foraging activity either restricted to or increased on moonlit nights. The artificial light from nearby urban centers may extend the number of hours such species spend foraging at night, and this has indeed been demonstrated for shorebirds feeding on mudflats ${ }^{24,35}$. Conversely, prey species may experience increased predation rates or, where mobile, reduced foraging times as a consequence of predator avoidance. For example, the diel vertical migration of zooplankton is a light intensity dependent behaviour which is thought to reduce predation risk ${ }^{36}$. However this migration has been observed to be suppressed in freshwater lakes above which the night-time sky is artificially brightened ${ }^{30}$. Many behaviours are often synchronized to short term variations in the 


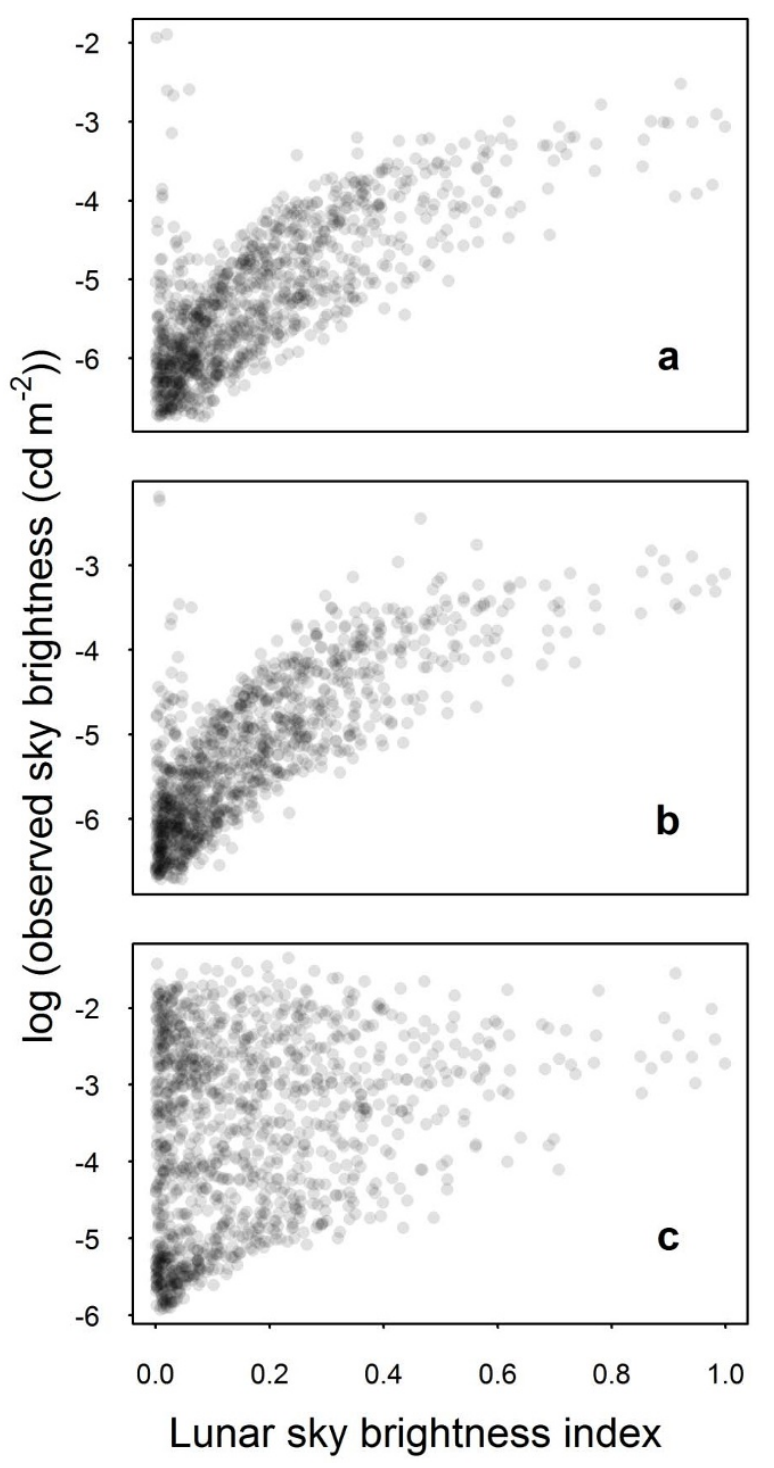

Figure 3 | City sky brightness correlates weakly with predictions based on lunar activity. The correlation between observed sky brightness and the predicted natural regime of lunar sky brightness is presented for $19.7 \mathrm{~km}$ (a), $8.6 \mathrm{~km} \mathrm{(b)} \mathrm{and} 0 \mathrm{~km} \mathrm{(c)} \mathrm{from} \mathrm{Plymouth} \mathrm{city} \mathrm{centre.} \mathrm{Points} \mathrm{are} \mathrm{plotted}$ with transparency to provide an information about density (darker regions correspond to denser aggregations of points). Observations are plotted for the period between 01/10/2011 and 31/07/2012. Each point represents an hourly recording of sky brightness, with recordings made when the moon was below the horizon, and when SQMs threshold at maximum brightness omitted (see methods).

illumination of the moon's disk throughout each 30 day phase period, a phenomenon which is widespread throughout the animal kingdom ${ }^{29,32,37-42}$. Hence, the short term destabilization of monthly lunar sky brightness regimes by artificial lights may disrupt patterns in foraging and mating linked to these phase periods. The increase in the magnitude of sky glow by artificial lights in cities is also likely to affect these behaviours and, in addition, may interfere with the navigation of many species which use celestial patterns of light to orientate themselves in the night-time environment ${ }^{43,44}$. For example, artificial light has been shown to disrupt the orientation and therefore migration direction of birds ${ }^{45}$, and concerns have been raised about the interference of artificial light pollution with celestial polarized sky light patterns ${ }^{28}$ which many insects ${ }^{46-50}$ and birds ${ }^{51,52}$ use to navigate.

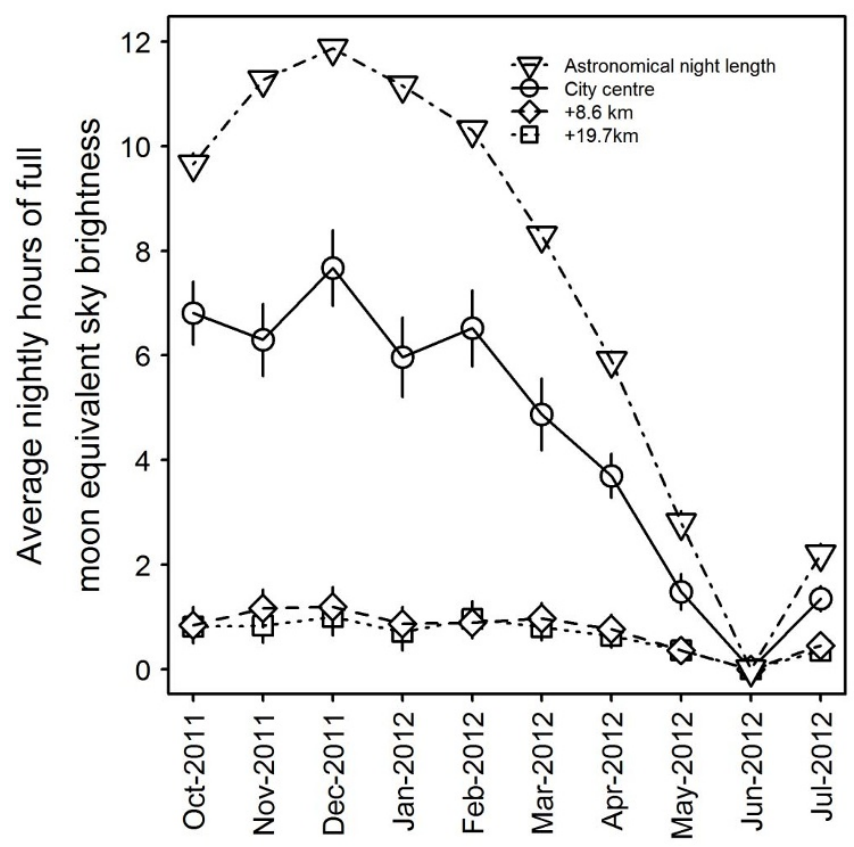

Figure $4 \mid$ City lights increase the nightly number of full moon equivalent hours more during winter months than summer months. The monthly variation in the number of hours per night when sky brightness was observed to be greater than the $3^{\text {rd }}$ quartile sky brightness observed in each month at a dark sky location ( $19.7 \mathrm{~km}$ from the city centre) when the moon is close to full ( $<45^{\circ}$ phase angle). Monthly average night length in hours is presented to illustate the natural annual variation in night length at the study locations. Error bars represent standard errors. Note that at the latitude of our locations, astronomical night does not occur during June.

Using a 10 month time series of sky brightness measurements, this study has revealed how artificial light pollution can alter the natural regimes of lunar sky brightness which regulate a variety of behaviours in many species. Yet few investigations have been conducted into what could be a plethora of potential ecological impacts of artificial sky glow. Understanding the environmental consequences of this already widespread ${ }^{3}$ and growing ${ }^{9}$ form of anthropogenic pollution is clearly essential.

\section{Methods}

Measuring night-time sky brightness. To achieve a gradient of light pollution, sky brightness was measured in Plymouth city centre, UK (50 22' 28.48" N:

$\left.408^{\prime} 19.04^{\prime \prime} \mathrm{W}\right), 19.7 \mathrm{~km}$ from the city centre in a 'dark' rural location $\left(5021^{\prime} 57.6\right.$ " $\mathrm{N}$ : $\left.424^{\prime} 53.01^{\prime \prime} \mathrm{W}\right)$, and at an intermediate rural location $8.6 \mathrm{~km}$ from the city centre (50 $19^{\prime} 01.72^{\prime \prime} \mathrm{N}: 413^{\prime} 11.32^{\prime \prime} \mathrm{W}$ ) (Figure 1). Plymouth is a city covering $79.78 \mathrm{~km}^{2}$, with a population of 240720 people and approximately 38000 municipal street lamps. Our rural sampling locations were situated on the coastline to the west of the city in order to minimize encroachment of artificial light from other urban centres. Sky brightness in magnitudes per square arc second (MPSAS) was measured every hour at each of the three locations using Sky Quality Meter Data Loggers (SQM-LU-DL, Unihedron) from the $01 / 10 / 2011$ to the $31 / 07 / 2012$. These values were then converted to $\mathrm{cd} \mathrm{m}^{-2}$ using $\left[\mathrm{cd} \mathrm{m}^{-2}\right]=10.8^{\mathrm{x}} 10^{4 \mathrm{x}} 10^{(-0.4 \times[\mathrm{MPSAS}])}$ which inverted the scale of the measurement so that it more intuitively represented sky brightness (brighter skies attain higher values). Each SQM -LU-DL was customised to record sky brightness directly up into the sky (elevation angle above the horizon of $90^{\circ}$ ) with a Half Width Half Maximum (HWHM) angular sensitivity of $\sim 10^{\circ}$. Each SQM -LU-DL was switched off in order to download data and recharge batteries for no more than seven days on two occasions during the sampling period.

Predicting night-time sky brightness. The natural regime of lunar sky brightness at zenith (in $\mathrm{nL}$ ) was predicted for the time of each data point recorded using equations $20,21,3$, and 15 of the moon light sky brightness model developed by Krisciunas \& Schaefe $^{33}$. The model estimates the lunar brightness of a given sky position above a specified geographical location at a given time under clear conditions based on the brightness of the moon $(I)$ estimated as a function of its' phase angle $(\alpha)$, the angular distance between the moon and the sky position being monitored $(\rho)$, the scattering of light across that distance $(f)$, and the extinction of light as it passes through the 
atmosphere $(k)$. The input parameters required to make the calculations are $\alpha, k$, and the zenith distance of the moon $(\mathrm{Zm})$ and the zenith distance of the sky position $(Z)$ which are used to calulate $\rho$. $Z$ is the angle between the zenith and the sky position for which calculations of brightness are derived. In this case the sky position observed by the SQM-LU-DL's was the zenith and therefore $Z$ was always $0^{\circ} . Z m$ was calculated as the moons altitude subtracted from the zenith $\left(90^{\circ}\right)$, hence $\rho$ was allways equal to $Z m$. The moons' altitude was calculated from the right ascension and declination of the moon relative to the geocentric coordinates of each of our SQM-LU-DL locations using equations 8.3 and 8.4 of Meeus ${ }^{53}$ respectively. $\alpha$ was estimated for each time point sampled using equations 31.2 and 31.3 of Meeus ${ }^{53}$. The model accounts for the lunar opposition effect by multiplying sky brightness values by 1.3 when the moon is less than $7^{\circ}$ phase angle ${ }^{33} . k$ is variable in both time and space, and depends on atmospheric conditions and height above sea level. Hence we assumed $k$ to be a constant value of 0.33 , equivalent to sea level $k$ under idealised conditions. In addition, the model does not account for variation in meterological conditions such as cloud, which can have a strong impact on sky brightness. This meant that the model predictions of lunar sky brightness were unlikely to match our observations in terms of magnitude. However, because we were interested in comparing only the correlation between temporal trends in observed sky brightness versus lunar sky brightness, this difference does not affect our conclusions. To avoid confusion, predicted lunar sky brightness is presented as an index between 0 and 1, with 1 corresponding to maximum predicted sky brightness during the observation period.

Statistical approach. All data recorded outside of astronomical night (when the sun is above $18^{\circ}$ below the horizon) were omitted to remove the influence of scattered sunlight on the analysis. This resulted in an absence of readings during June due to the lack of astronomical night at the latitude sampled when day lengths were at their maximum.

The degree of sychronicity between observed and predicted natural lunar regimes of sky brightness was tested independently for each sampling location using Pearson correlations. A known problem occurs with early firmware versions on SQM-LU-DLs leading to recorded sky brightness thresholding, resulting in frequent recordings of minimum brightness which introduces a strong degree of leverage into the dataset. All records of maximum readings for each SQM-LU-DL were therefore omitted from Figures 2 and 3, and correlative analysis, to avoid this effect. The output from the lunar sky brightness model does not calculate sky brightness due to starlight, and assuming a constant value of 21.6 MPSAS on the numerous recordings during which the moon was below the horizon introduced a strong degree of leverage into the data. Therefore all recordings made when the moon was below the horizon were omitted from these analysis also.

To demonstrate how changes in sky brightness regimes affect the number of hours of full moon equivalent sky brightness per night throughout the year, we re-analysed the SQM recordings including data points which had previously been omitted due to frequent recordings of minimum sky brightness and periods when the moon was below the horizon. For each sampling location, we then calculated the number of hours per night when sky brightness was above that when the moon is close to full and compared this between sampling locations. For the purposes of this analysis, the threshold for close to full moon sky brightness was defined as the $3^{\text {rd }}$ quartile observation made when the moon is between three-quarters and full $\left(<45^{\circ}\right.$ phase angle) in each individual month at the 'dark' (19.7 km) location. This was defined independently for each month because the brightness of the full moon varies with its maximum altitude throughout the year (Figure 2d). Observations made during the third quarter to full moon were used to define full moon equivalent brightness because the number of observations made when the moon is full varies between months, with few observations occuring in summer months. The $3^{\text {rd }}$ quartile observation was used as the cut off in each month to ensure full moon equivalent sky brightness was defined by the brightest nights, while avoiding the influence of outliers which can have a large effect on the mean.

The nightly number of hours where sky brightness was greater than average full moon sky brightness was compared between months (factor Month) and sampling locations (factor Site), and tested for a difference in the annual regime between sampling locations (Month*Site interaction). To account for the many nights that contained 0 hours when the sky was brighter than sky brightness during a full moon, we performed our analysis using Zero Adjusted Poisson Regression (ZAP).

1. Smith, M. Time to turn off the lights. Nature 457, 27-27 (2009).

2. Falchi, F., Cinzano, P., Elvidge, C. D., Keith, D. M. \& Haim, A. Limiting the impact of light pollution on human health, environment and stellar visibility. J. Environ. Manage. 92, 2714-2722 (2011).

3. Cinzano, P., Falchi, F. \& Elvidge, C. D. The first world atlas of the artificial night sky brightness. Mon. Not. R. Astron. Soc. 328, 689-707 (2001).

4. Gallaway, T. On light pollution, passive pleasures and the instrumental value of beauty. J. Econ. Issues 44, 71-88 (2010).

5. Longcore, T. \& Rich, C. Ecological light pollution. Front. Ecol. Environ. 2, 191-198 (2004)

6. Hölker, F., Wolter, C., Perkin, E. K. \& Tockner, K. Light pollution as a biodiversity threat. Trends Ecol. Evol. 25, 681-682 (2010).

7. Gaston, K. J., Davies, T. W., Bennie, J. \& Hopkins, J. Reducing the ecological consequences of night-time light pollution: options and developments. J. App. Ecol. 49, 1256-1266 (2012).
8. Navara, K. J. \& Nelson, R. J. The dark side of light at night: physiological, epidemiological, and ecological consequences. J. Pineal Res. 43, 215-224 (2007)

9. Holker, F. et al. The dark side of light: a transdisciplinary research agenda for light pollution policy. Ecol. Soc. 15 (2010).

10. Walker, M. F. The effects of urban lighting on the brightness of the night sky. Publ. Astron. Soc. Pac. 89, 405-409 (1977).

11. Cinzano, P. \& Elvidge, C. D. Night sky brightness at sites from DMSP-OLS satellite measurements. Mon. Not. R. Astron. Soc. 353, 1107-1116 (2004).

12. Zoltan, K. Measuring and modelling light pollution at the Zselic starry sky park. JPCS 218, 012001 (2010).

13. Miller, J. R. Biodiversity conservation and the extinction of experience. Trends Ecol. Evol. 20, 430-434 (2005)

14. Merkel, F. R. Light-induced bird strikes on vessels in Southwest Greenland. Technical Report No. 84, Pinngortitaleriffik, Greenland Institute of Natural Resources (2010).

15. Rodríguez, A. et al. Factors affecting mortality of shearwaters stranded by light pollution. Anim. Conserv. 15, 519-526 (2012)

16. Witherington, B. E. Behavioral responses of nesting sea turtles to artificial lighting Herpetologica 48, 31-39 (1992).

17. McFarlane, W. N. Disorientation of Loggerhead hatchlings by artificial road lighting. Copeia 1, 153-153 (1963).

18. Eisenbeis, G. in Ecological consequences of artificial night lighting (eds C. Rich \& T. Longcore), Ch. 12, 281-304 (Island Press, 2006).

19. Frank, K. D. in Ecological consequences of artificial night lighting (eds C. Rich \& T. Longcore), Ch. 13, 305-344 (Island Press, 2006).

20. Stone, E. L., Jones, G. \& Harris, S. Street lighting disturbs commuting bats. Curr. Biol. 19, 1123-1127 (2009).

21. Polak, T., Korine, C., Yair, S. \& Holderied, M. W. Differential effects of artificial lighting on flight and foraging behaviour of two sympatric bat species in a desert. J. Zool. 285, 21-27 (2011).

22. Santos, C. D. et al. Effects of artificial illumination on the nocturnal foraging of waders. Acta Oecol. 36, 166-172 (2009).

23. Titulaer, M., Spoelstra, K., Lange, C. Y. M. J. G. \& Visser, M. E. Activity patterns during food provisioning are affected by artificial light in free living Great Tits (Parus major). Plos One 7, e37377 (2012).

24. Dwyer, R. G., Bearhop, S., Campbell, H. A. \& Bryant, D. M. Shedding light on light: benefits of anthropogenic illumination to a nocturnally foraging shorebird. J. Anim. Ecol. 82, 478-485 (2013).

25. Davies, T. W., Bennie, J. \& Gaston, K. J. Street lighting changes the composition of invertebrate communities. Biol. Lett. 8, 764-767 (2012).

26. Kelber, A. et al. Light intensity limits foraging activity in nocturnal and crepuscular bees. Behav. Ecol. 17, 63-72 (2006).

27. Fernandez-Duque, E. \& Erkert, H. G. Cathemerality and lunar periodicity of activity rhythms in owl monkeys of the Argentinian Chaco. Folia Primatol. 77, 123-138 (2006)

28. Kyba, C. C. M., Ruhtz, T., Fischer, J. \& Hölker, F. Lunar skylight polarization signal polluted by urban lighting. J. Geophys. Res. D 116, D24106 (2011).

29. Mercier, A., Ycaza, R. H. \& Hamel, J. F. Long-term study of gamete release in a broadcast-spawning holothurian: predictable lunar and diel periodicities. Mar. Ecol. Prog. Ser. 329, 179-189 (2007).

30. Moore, M. V., Pierce, S. M., Walsh, H. M., Kvalvik, S. K. \& Lim, J. D. Urban light pollution alters the diel vertical migration of Daphnia. Verh. Internat. Verein Limnol. 27, 1-4 (2000).

31. Oehmke, M. G. Lunar periodicity in flight activity of honey bees. J. Interdiscipl. Cycle 4, 319-335 (1973).

32. Tanner, J. Seasonality and lunar periodicity in the reproduction of Pocilloporid corals. Coral Reefs 15, 59-66 (1996).

33. Krisciunas, K. \& Schaefer, B. E. A model of the brightness of moonlight. Publ. Astron. Soc. Pac. 103, 1033-1039 (1991).

34. Kyba, C. C. M., Ruhtz, T., Fischer, J. \& Holker, F. Cloud coverage acts as an amplifier for ecological light pollution in urban ecosystems. Plos One 6, e17307 (2011).

35. Rojas, L., McNeil, R., Cabana, T. \& Lachapelle, P. Diurnal and nocturnal visual capabilities in shorebirds as a function of their feeding strategies. Brain Behav. Evolut. 53, 29-43 (1999).

36. Cohen, J. H. \& Forward, R. B. Zooplankton diel vertical migration - a review of proximate control. Oceanogr. Mar. Biol. 47, 77-110 (2009).

37. Gerrish, G. A., Morin, J. G., Rivers, T. J. \& Patrawala, Z. Darkness as an ecological resource: the role of light in partitioning the nocturnal niche. Oecologia 160, 525-536 (2009)

38. Vignoli, L. \& Luiselli, L. Better in the dark: two Mediterranean amphibians synchronize reproduction with moonlit nights. Web Ecol. 13, 1-11 (2013).

39. Penteriani, V., Kuparinen, A., Delgado, M. D. M., Lourenço, R. \& Campioni, L. Individual status, foraging effort and need for conspicuousness shape behavioural responses of a predator to moon phases. Anim. Behav. 82, 413-420 (2011).

40. Smit, B., Boyles, J. G., Brigham, R. M. \& McKechnie, A. E. Torpor in dark times: patterns of heterothermy are associated with the lunar cycle in a nocturnal bird. J. Biol. Rhythms 26, 241-248 (2011).

41. Jetz, W., Steffen, J. \& Linsenmair, K. E. Effects of light and prey availability on nocturnal, lunar and seasonal activity of tropical nightjars. Oikos 103, 627-639 (2003). 
42. Baker, G. C. \& Dekker, R. W. R. J. Lunar synchrony in the reproduction of the Moluccan Megapode Megapodius wallacei. Ibis 142, 382-388 (2000).

43. Dacke, M., Byrne, M. J., Baird, E., Scholtz, C. H. \& Warrant, E. J. How dim is dim? Precision of the celestial compass in moonlight and sunlight. Phil. Trans. R. Soc. B 366, 697-702 (2011).

44. Warrant, E. \& Dacke, M. Vision and visual navigation in nocturnal insects. Annu. Rev. Entomol. 56, 239-254 (2011).

45. Wiltschko, W., Munro, U., Ford, H. \& Wiltschko, R. Red light disrupts magnetic orientation of migratory birds. Nature 364, 525-527 (1993).

46. Dacke, M., Nilsson, D.-E., Scholtz, C. H., Byrne, M. \& Warrant, E. J. Animal behaviour: insect orientation to polarized moonlight. Nature 424, 33-33 (2003).

47. Herzmann, D. \& Labhart, T. Spectral sensitivity and absolute threshold of polarization vision in crickets: a behavioral study. J. Comp. Physiol. A 165 315-319 (1989).

48. Mappes, M. \& Homberg, U. Behavioral analysis of polarization vision in tethered flying locusts. J. Comp. Physiol. A 190, 61-68 (2004).

49. Wehner, R. The hymenopteran skylight compass: matched filtering and parallel coding. J. Exp. Biol. 146, 63-85 (1989).

50. Zufall, F., Schmitt, M. \& Menzel, R. Spectral and polarized light sensitivity of photoreceptors in the compound eye of the cricket (Gryllus bimaculatus). J. Comp. Physiol. A 164, 597-608 (1989).

51. Cochran, W. W., Mouritsen, H. \& Wikelski, M. Migrating songbirds recalibrate their magnetic compass daily from twilight cues. Science 304, 405-408 (2004).

52. Muheim, R., Phillips, J. B. \& Åkesson, S. Polarized light cues underlie compass calibration in migratory songbirds. Science 313, 837-839 (2006).

53. Meeus, J. Astronomical formulae for calculators. Fourth edn, 218 (William-Bell, Inc., 1988).

\section{Acknowledgements}

We would like to thank the University of Plymouth, the staff of Rame Head coast watch station, and the staff of the Monkey Sanctuary, Looe for allowing us to deploy our SQM-LU-DLs on their buildings. The research leading to this paper has received funding from the European Research Council under the European Union's Seventh Framework Programme (FP7/2007-2013)/ERC grant agreement no. 268504 to K.J.G.

\section{Author contributions}

T.D., K.J.G. and J.B. conceived the study. T.D., J.B. and K.J.G. designed the study. T.D. collected the data. T.D. and J.B. conducted the analysis. T.D. wrote the first draft of the manuscript. All authors contributed to revisions.

\section{Additional information}

Competing financial interests: The authors declare no competing financial interests.

License: This work is licensed under a Creative Commons

Attribution-NonCommercial-NoDerivs 3.0 Unported License. To view a copy of this license, visit http://creativecommons.org/licenses/by-nc-nd/3.0/

How to cite this article: Davies, T.W., Bennie, J., Inger, R. \& Gaston, K.J. Artificial light alters natural regimes of night-time sky brightness. Sci. Rep. 3, 1722; DOI:10.1038/ srep01722 (2013) 